\title{
Exterior nest-boxes may negatively affect Barn Owl Tyto alba survival: an ecological trap
}

\author{
ÁKOS KLEIN, TIBOR NAGY, TIBOR CSÖRGŐ and RÓBERT MÁTICS
}

\begin{abstract}
Summary
Nest-site reduction has played a significant role in the decline of Barn Owl Tyto alba populations throughout Europe and North America. Techniques of nest-site augmentation, involving the provision of nest-boxes, have been widely used in a range of species of conservation concern, including falcons, eagles, parrots, owls and cavity-nesting ducks. A common method of Barn Owl conservation is the placement of nest-boxes on church towers. Despite the usefulness of nestboxes, several studies have shown that there may be associated disadvantages and that nestboxes may even act as 'ecological traps'. The purpose of this research was to compare the survival rate of owlets hatched in nest-boxes with those hatched in the more "natural" environment of church towers. Survival time analysis elucidated that owlets developing in nest-boxes had significantly lower survival than those hatched in church towers. This difference was most obvious after the parent-dependent period of the life history. Surprisingly, the length of time from hatching to the onset of winter had no effect on the survival of the owlets, even though the accumulation of sufficient body reserves and acquisition of hunting experience are thought to be important in determining survival during the critical first winter of life. We propose possible causes for the negative effects of nest-boxes and recommend some modifications to the priorities of Barn Owl Action Plans, e.g. partial reopening of buildings instead of nest-box installation. This paper emphasizes the importance of considering revision of Species Action Plans in the case of other endangered species where conservation is based on nest-site supplement (e.g. hornbills, cavity-nesting seabirds, European Roller Coracias garrulus, Little Owl Athene noctua, Saker Falcon Falco cherrug, White Stork Ciconia ciconia).
\end{abstract}

\section{Introduction}

The three main approaches of bird conservation action plans are habitat management, nest-site supplementation and public awareness campaigns. Nest-site supplementation can be critical in species which have specific nesting requirements since the availability of nest-sites is a major limiting factor. These species either do not build their own nests (e.g. falcons, owls), or need a suitable hole or cavity to nest in (e.g. parrots, tits, flycatchers, hornbills). Obligate secondary cavity-nesters are the best-known group whose populations can be affected by the loss of available nest-sites due to the changing environment (Eadie et al. 1998). If the correlation between nest-site availability and the local abundance of hole-nesting birds can be proven, artificial nest-site supplementation is a possible way to conserve threatened taxa (Newton 1994). Increasing the availability of secure nest-sites can lead to an increase in the size of the breeding population and breeding success, as shown, inter alia, for Madeiran Storm Petrels Oceanodroma castro (Bolton et al. 2004). There is also evidence that the abundance of Sumba's large parrot species (but not the hornbill species) strongly depends on the availability of suitable nest-sites (Marsden and Jones 1997) and that interspecific competition between exotic hollow-users (e.g. European Starling Sturnus vulgaris in Australia) may constitute a threat to breeding success of 
native cavity-nesting species such as rosellas (Pell and Tidemann 1997). Despite the potential usefulness, there are several studies showing that artificial nest-site supplements may have as many costs as benefits (Møller 1989, Gowaty and Bridges 1991, Eadie et al. 1998, Mebs and Scherzinger 2000). In extreme cases, conservation and management protocols may act as ecological traps, which can lead to extinction if a population falls below a critical threshold size (Schlaepfer et al. 2002). If nest-site provision is considered to be a key factor in the conservation of a given cavity-nesting species, nesting requirements of the target species and the possible effects of the conservation methods must be examined thoroughly.

The Barn Owl Tyto alba has a worldwide distribution but has been protected since the early 1970 s using methods based mainly on nest-box provision. Although not globally threatened with extinction, it is listed in Cites Appendix II, and its populations have been declining for about 50 years in Europe and North America (Bruce 1999). In the major part of Europe, between 1970 and 1990 a decrease of $20 \%$ was reported (Hagemeijer and Blair 1997), and the species became extinct in Malta. Conservationists cite changes to the global agricultural landscape (Colvin 1985), loss of nest-sites and increases in vehicle traffic from expanding road networks (Fajardo 2001, Mátics 2000, Mátics 2005) as the most important factors in their decline. The Barn Owl is a secondary cavity-nesting owl species, which in the past naturally bred in tree-holes and cliff cavities (Cramp 1985). Nowadays in Europe, the proportion of pairs breeding in tree-cavities is very low (Taylor 1994). The main reason for this is the decline in natural woodland coverage within Hungary, which had been reduced from $80 \%$ to $11 \%$ by the nineteenth century (Lovász and Nagyváradi 1997). Since the most suitable types of habitats, such as riverine and sylvopastural woodland and patches of forest steppe, have mostly disappeared, Barn Owls in the Carpathian Basin have started to breed in buildings, especially in church towers (König et al. 1999). The cause of further decline has been the closing of spire apertures to lock out Rock Doves Columba livia, Jackdaws Corvus monedula, etc. (Golawski 2003, Klein et al. 2003). A common practice to conserve Barn Owls has been the placement of nest-boxes, fixed tightly to the towerwindow, with the entrance looking outwards, so that the owls cannot fly into the building (Bunn et al. 1982, Shawyer 1987, Taylor 1994).

We intended to determine whether there is any relationship between the nest type and laying date. Since the duration of snow cover and low temperatures in winter are the main factors determining mortality rates in continental European Barn Owl populations (Taylor 1994, Altwegg et al. 2003), we supposed that the time from laying to the onset of winter can influence survival of the owlets. Since nest-site supplementation can be critical in long-term Barn Owl conservation in Europe, the main objective of the present study was to elucidate how nest-box provision affects the short-term survival of Barn Owls. In other words: is the type of nest-site (nest-box in church tower or church tower without nest-box) related to differences in survival within the first year of the Barn Owls' life?

\section{Methods}

\section{Data collection}

We examined an 8-year period between 1995 and 2003. The Hungarian Bird Ringing Centre provided the data. As the Barn Owl is a commensal and resident species (Mikkola 1983, Marti 1999), a large proportion of the marked population can be recaptured, which provides a sound basis for ring-recapture analysis. Data covered the entire territory of Hungary and included all details according to the European Bird-ringing Schemes (EURING), such as ring number, date, body condition, circumstances, latitude and longitude. However, there was no information on the type of nest-site (e.g. nest-box, spire, barn, tree-cavity) as ringers are not required to report this. We therefore contacted each ringer personally and managed to collect reliable data on the origin of 8,130 ringed individuals. From the 8,130 specimens 437 were recovered and 297 of the 437 were marked as owlets. The various nest-sites (church towers with and without nest-boxes) were distributed randomly within the total sample. 


\section{Data treatment and analysis procedure}

Data were analysed by survival time analysis (STA), which is appropriate where data are collected over time by repeatedly observing uniquely identified individuals (Fox 2001).

We used the following variables in the analysis: nest-site (nest-box, NB; church tower, CT); relative laying date (the first registered laying date in each year is the zero point); number of days left until I November (which is considered the starting date of severe winter); ringing and recapture year, month and day; failure-time and censored-uncensored state. Dead-recovery events $(n=163)$ were considered uncensored, live-recapture occasions $(n=88)$ censored data points. It should be noted that STA is not able to correct for the effect of different recovery rates belonging to the groups of interest. For this reason, we firstly used non-parametric tests such as the $\chi^{2}$ test and Fisher's Exact test (Zar 1974) to help to identify any biases in recoveries.

While performing STA, we divided the whole period (o-2,I71 days) into several intervals referring to stages of the life history (Table 1 ). Ringing took place mostly around the age of 40 days, and the date of ringing is equivalent to day o in STA. Individuals recaptured 20-30 days later (they were about 60-70 days old) were fledglings that had already left the nest (Roulin 1999). Another 30 days later (at an age of $c$. 90 days) fledglings become entirely independent (König et al. 1999) and parents stop feeding their chicks. Thus, data on roughly the first 50 days represent survival until becoming independent. The 385 day period is known as the first survival year.

Survival time analysis was performed according to Fox (2001) and Renner and Davis (2001) using the STAT 7.0 package. We fitted several theoretical distributions provided by Fox (2001) to our subgroups to find the most suitable one (number of intervals: 25). We obtained the best fit with the Weibull distribution, which is one of the most widely used two-parametric distributions in STA. For regression analysis, we applied the semi-parametric Cox's proportional hazard regression model, which is suitable if the failure-time data fit well to the theoretical Weibull distribution (Kalbfleisch and Prentice 1980). To avoid pseudoreplication arising from recaptures of several fledglings originating from the same nest, we entered siblings as clusters into the analysis (Renner and Davis 2001) and took the average of the variables. After this correction, we had 252 independent data points: 104 owlets ringed in nest-boxes and 148 in church towers.

For the comparisons, we used the following null hypothesis: The frequency of recapture does not depend on the type of nest-site where the chicks hatched. We also reasoned that the type of brood-site would have most impact within the first year. We wanted to avoid artefacts arising from a biased encounter rate, which might be significant around the nest-sites (8-week-old fledglings leave the nest-box before it is opened, whereas one can easily catch even an adult bird in the spire). Therefore, we excluded the first 50 days from the final analysis.

\section{Results}

\section{Ringing activity and recoveries}

Fewer adults were ringed in nest-boxes than in open breeding places $\left(\chi^{2}\right.$ test; $n_{\mathrm{CT}}=582, n_{\mathrm{NB}}=$ 94 , expected $=338, \chi^{2}{ }_{1}=202, P<$ O.01) and birds ringed in nest-boxes were recovered in a lower proportion as well $\left(\chi^{2}\right.$ test; $n_{\mathrm{CT}_{\text {_ringed }}}=582, n_{\mathrm{NB} \_ \text {ringed }}=94, n_{\mathrm{CT} \text { _recovered }}=133$, $n_{\mathrm{NB} \_ \text {recovered }}=7, \chi_{1}^{2}=8.48, P<$ o.01). Fewer juveniles were ringed in nest-boxes than in

Table 1 . The difference between the real age of owlets and the coding for survival time analysis (STA).

\begin{tabular}{llllll}
\hline & Hatching & Ringing & Fledging & $\begin{array}{l}\text { Extra-nest-site } \\
\text { parental care }\end{array}$ & $\begin{array}{l}\text { First year after } \\
\text { fledging }\end{array}$ \\
\hline Age of owlets (days) & 0 & c. 40 & 60 & 90 & 425 \\
Timing in STA & - & 0 & 20 & 50 & 385 \\
\hline
\end{tabular}

Ringing of birds (day o in STA) usually occurs at the age of 40 days. 
church towers ( $\chi^{2}$ test; $n_{\mathrm{CT}}=4059, n_{\mathrm{NB}}=3395$, expected $=3727, \chi_{1}^{2}=29.6, P<0.01$ ), but the proportion of recoveries among birds marked as owlets did not differ between the two types of brood sites $\left(\chi^{2}\right.$ test; $n_{\text {CT_ringed }}=4059, n_{\text {NB_ringed }}=3395, n_{\text {CT_recovered }}=176, n_{\text {NB_recovered }}=121$, $\left.\chi^{2}{ }_{1}=2.66, P=0.10\right)$.

\section{The effect of breeding site}

\section{Period $0-2,171$ days}

Birds ringed as owlets and hatched in nest-boxes were found dead in a greater ratio than those hatched in church towers (Fisher's Exact test; $n=297, P=0.02$ ). After clustering the siblings the difference persisted (Fisher's Exact test; $n=252, P=0.04$ ) (Table 2). However, when applying STA to the whole dataset, the log-rank test showed that there was no difference in respect of failure time between the two groups $(\mathrm{WW}=7.56$, Sum $=158.79$, Var $=38.64$, test statistic $=1.22, P=0.22)($ Table 2$)$.

\section{Period $0-385$ days}

For the first year of life both non-parametric and STA tests showed significant differences (Fisher's exact test; $n=191, P=0.04 ; \log$-rank test, test statistic $=1.96, P=0.049$ ).

\section{Period 50-385 days}

Comparing survival during the first year, but after the 50 day period when owlets are dependent upon their parents, cumulative proportion surviving functions differ strongly between the two groups (log-rank test, test statistic $=-2.07, P=0.038$ ). However, Fisher's Exact test could not detect any significant differences $(n=156, P=0.12)$. Displaying cumulative survival function against time (according to the Kaplan-Meier product limit method) showed that the survival functions become different after c. Ioo days (Figure 1).

\section{Period 385-2,171 and 0-50 days}

Neither of these two periods showed significant differences in recovery frequencies (Fisher's Exact test; $n=61, P=0.60$ and $n=36, P=0.29$, respectively) or cumulative survival (log-rank test; test statistic $=1.25, P=0.21$ and test statistic $=1.81, P=0.07$, respectively) (Table 2).

Table 2. Results of a non-parametric Fisher's Exact test and survival time log-rank test statistics regarding the comparison of the two brood-sites.

\begin{tabular}{|c|c|c|c|c|c|c|c|}
\hline \multirow[t]{2}{*}{ Intervals } & \multicolumn{2}{|c|}{ Nest-box } & \multicolumn{2}{|c|}{ Church tower } & \multirow[t]{2}{*}{$N$} & \multirow[t]{2}{*}{ Fisher's Exact test } & \multirow[t]{2}{*}{ Log-rank test } \\
\hline & Dead & Alive & Dead & Alive & & & \\
\hline $0-2,171$ & 75 & 29 & 88 & 60 & 252 & $P=0.045$ & $P=0.22$ \\
\hline $0-385$ & 56 & 19 & 70 & 46 & 191 & $P=0.044$ & $P=0.049$ \\
\hline $50-385$ & 47 & 16 & 58 & 35 & 156 & $P=0.12$ & $P=0.038$ \\
\hline $385-2,171$ & 19 & 10 & 18 & 14 & 61 & $P=0.60$ & $P=0.21$ \\
\hline $0-50$ & 9 & 3 & 3 & 11 & 36 & $P=0.29$ & $P=0.069$ \\
\hline
\end{tabular}

Intervals show the particular life history stages (for details see Methods; values with $P<0.05$ are shown in bold). 


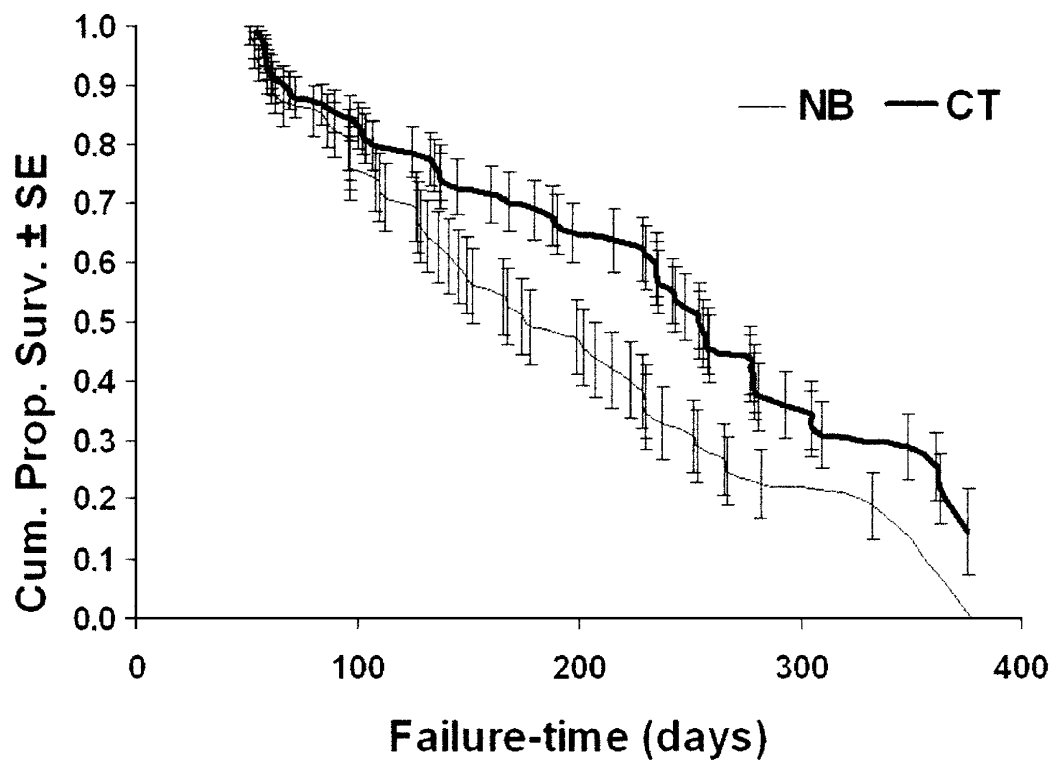

Figure 1. The Kaplan-Meier cumulative survival function of owlets hatched in church towers (CT) and nest-boxes (NB). Error bars represent standard errors of means.

\section{The effect of hatching time (laying date)}

Considering the period between days 50 and 385 only, the number of days left until I November did not have any effect on the difference between survival of birds hatched in church towers and nest-boxes (Cox's proportional hazard regression; $\chi^{2}{ }_{1}=0.13, P=0.72$ ). Even with the relative laying-date entered as an independent variable, the result displayed no change (Cox's proportional hazard regression; $\chi^{2}{ }_{1}=0.68, P=0.41$ ).

\section{Discussion}

The main finding of this study is that the short-term survival of the owlets from nest-boxes is lower than that of owlets hatched in the more natural church towers during the parentindependent period of their first year $(50-385$ days). This result implies that when the owlets leave the vicinity of the parental nest and begin their independent life, their chance of survival, to an extent, depends upon the breeding place of their parents.

Even though nest-box installation is traditionally thought to be the most effective Barn Owl conservation method throughout Europe (Bunn et al. 1982, Shawyer 1987, Taylor 1994), and is clearly better than having no nesting opportunities at all, our results suggest that this method of protection has major disadvantages. It is therefore a realistic hypothesis to conclude that Barn Owl nest-boxes act as 'ecological traps' in the sense that when man suddenly alters the environment, formerly reliable cues might no longer be associated with adaptive outcomes, which can cause reduced survival or reproduction (Schlaepfer et al. 2002). Barn Owls used to nest mostly in tree-cavities and cliff-holes until a few hundred years ago. Since Barn Owl nestboxes are generally installed high up in church towers, and imitate dark cavities in large trees, Barn Owls may choose this kind of nest-site over other possibilities such as open roofs or spires. If a significant proportion of the population breeds in nest-boxes, which can negatively affect the survival of the owlets, the decreased survival can lead to population instability or decline. 
There are substantial differences between nest-boxes and natural nest-sites such as treecavities or church towers. It is likely that these have a number of implications for the survival of young:

(I) Barn Owl chicks, similarly to those of other strigid owlets, are altricial; however, they tend to leave the nest when still covered in down and unable to fly (Bruce 1999). Until they reach the full-fledged stage of development, young owls stay close to the nest-cavity, walk along adjacent branches, and practise flying, perching and balancing on the trees close to the nest. The first flight from nest-boxes, however, often happens without any previous practice, because nest-boxes are in the highest part of tall buildings $(20-30 \mathrm{~m})$. In church towers with no nest-boxes, young owls are able to practise flying inside the spire and they do not leave the building for several weeks. This way they obtain a certain amount of practice, which is missing in case of the owlets hatched in nest-boxes.

(2) Human disturbance can be more prevalent around nest-boxes than in church towers. During inspections of nest-boxes and ringing procedures, adult birds leave the box in almost every case before or during the opening of the lid. In contrast, in church towers, parents often hide in a corner, and do not leave the nest-site. Our results support this observation, because only $14 \%$ of the marked adults were ringed in nest-boxes between 1995 and 2003. This difference might be important during incubation and in the case of newly hatched owlets, because the owlets, may not yet be ready for independent thermoregulation (Cramp 1985, Toms 1998).

(3) Mebs and Scherzinger (2000) suggest that there are more sterile eggs in nest-boxes since copulations are less efficient due to limited space.

(4) Finally, several studies indicated that unnatural density, height, appearance (Gowaty and Bridges 1991, Eadie et al. 1998) and the age of nest-boxes (Vilka 2003) can strongly change population dynamics by altering behaviour (e.g. conspecific brood parasitism). The hypotheses put forward under points 2 and 3 are weakened by the fact that, to our knowledge, no study has found a difference in numbers of hatched and fledged young with respect to the two types of brood-sites. There has been an attempt to test this hypothesis based on breeding parameters, but the available data did not show a significant difference between the numbers of hatched eggs or fledged chicks (M. R., unpubl. data).

The significant difference in cumulative surviving function was observable after 100 days (Figure 1). This period is very close to early winter, depending on the laying date. Winter, particularly the first winter, is a critical period in the life of the Barn Owl, because of the inability of this species to accumulate sufficient body reserves compared with other raptors of the same size (Handrich et al. 1993, Massemin et al. 1997). Surprisingly, date of hatching and the time remaining until the onset of winter ( 1 November) did not influence the difference found in survivorship curves. We did not investigate the direct mechanisms which might explain this bias in survival; however, difference in the growth and development of owlets, parasite load, competition and aggression among siblings and microclimate in nest-sites may all be responsible for the differential survival. Experimental testing of these factors could be the subject of further investigations.

Nest-box installation is only one possible way to conserve Barn Owls in church towers. In most of Europe, where Barn Owl breeding occurs frequently in church towers, the best longterm solution would be to separate the dome from the rest of the tower, because this way there would be sufficient space remaining for the owlets, and they would be unable to fall from their nest-sites (Mebs and Scherzinger 200o). At the same time, the faeces and pellets produced by the birds would stay in a place where they do not disturb the users of the building. It is always questionable, however, whether a new approach to conservation will be acceptable to the given community (in this case to churchmen). According to a survey conducted in 1999 by the Hungarian Barn Owl Protection Foundation, 63\% of the 300 people questioned (priests, chaplains, presbyters, etc.) supported the complete or partial reopening of the church they 
manage, $11 \%$ did not allow any conservation activity in the buildings, and $16 \%$ supported only nest-box installation (Hungarian Barn Owl Protection Foundation, unpubl. data). This survey of churchmen's attitudes verifies that our proposals would meet a favourable response in most cases.

We emphasize the importance of similar revisions of Species Action Plans in the case of other threatened species including large eagles, falcons, owls, rollers, parrots and rare passerines where nest-site supplementation is the keystone of the Plan. We have found only a few studies that deal with the establishment of new conservation methods or the evaluation of those already applied (see Gil-Sánchez et al. 2004 (Bonelli's Eagle Hieraaetus fasciatus), Gowaty and Bridges, 1991 (Eastern Bluebird Sialia sialis), Marsden and Jones, 1997 (Sumba's parrots and endemic hornbill) and Pell and Tidemann, 1997 (native Australian parrots)).

Artificial nest-site provision in North American Wood Ducks Aix sponsa and Barrow's Goldeneyes Bucephala islandica actually caused populations to decline (Eadie et al. 1998). In this case, nest-boxes were installed in close proximity to each other, which created a colonial nesting situation for a species that nests solitarily. The frequency of conspecific brood parasitism increased, which led to inefficient incubation of supernormal clutches, reduced egg hatching success, followed by a population decline. Mänd et al. (2005) found supra-optimal breeding densities in their Great Tit Parus major population, caused by artificial improvement of nest-site availability, leading to a lesser number of young fledged per nest, and decreased return rate compared with the suboptimal habitat. On the other hand, nest-site supplementation can be an effective conservation tool if the natural nesting requirements of the species are considered carefully. The Hungarian population of the globally threatened Saker Falcon Falco cherrug increased from 8 pairs to 120 pairs during the last 25 years. This population depends largely on nest-site supplementation, because today almost $95 \%$ of pairs breed in artificial nests (Bagyura et al. 2003).

Finally, we encourage conservationists to use survival time analysis performed on ringrecapture data, because this method does not expose birds to further disturbance, it is not an invasive technique and can successfully be applied in every species where a high proportion of individuals can be ringed and recaptured. There are several studies based on survival time analysis demonstrating how important nest-site selection can be from the perspective of population management (Li and Martin 1991, Paredes and Zavalaga 2001, Renner and Davis 2001, Liebezeit and George 2002).

\section{Acknowledgements}

We would like to thank the Hungarian Bird Ringing Centre, the Hungarian Barn Owl Protection Foundation and all ringers for the data provided. D. Forman, R. Hargitai, A. Hettyey, E. Kniprath and two anonymous referees made valuable comments on the manuscript. We are grateful to T. Bantock for grammatical corrections to the English. R. M. was supported by OTKA Grant No. To25822, Á. K. by Bureau of Application in Higher Education No. FKFPoO21/2002.

\section{References}

Altwegg, R., Roulin, A., Kestenholz, M. and Jenni, L. (2003) Variation and covariation in survival, dispersal, and population size in Barn Owls Tyto alba. J. Anim. Ecol. 72: 391-399.

Bagyura, J., Szitta, T., Hraszthy, L., Kállay, Gy., Demeter, I., Sándor, I., Dudás, M. and
Viszló, L. (2003) Population trend of the Saker Falcon (Falco cherrug) in Hungary between 1980 and 2002. Sixth World Conference on Birds of Prey and Owls, Budapest, World Working Group on Birds of Prey and Owls. Abstract, Volume 2. 
Bolton, M., Medeiros, R., Hothersall, B. and Campos, A. (2004) The use of artificial breeding chambers as a conservation measure for cavity-nesting procellariiform seabirds: a case study of the Madeiran storm petrel (Oceanodroma castro). Biol. Conserv. 116: 73-80.

Bruce, M. D. (1999) Family Tytonidae (Barnowls). Pp. $34-75$ in J. del Hoyo, A. Elliott and J. Sargatal, eds. Handbook of the birds of the world. Volume 5. Barn-owls to Hummingbird. Barcelona: Lynx Edicions.

Bunn, D. S., Warburton, A. B. and Wilson, R. D. S. (1982) The barn owl. Calton: T. \& A. D. Poyser.

Colvin, B. A. (1985) Common barn-owl population decline in Ohio and the relationship to agricultural trends. J. Field Ornithol. 56: 224-235.

Cramp, S. (1985) Handbook of the birds of Europe, the Middle East and North Africa, Volume 4. Oxford: Oxford University Press.

Eadie, J., Sherman, P. and Semel, B. (1998) Conspecific brood parasitism, population dynamics, and the conservation of cavitynesting birds. Pp. 306-340 in T. Caro, ed. Behavioral ecology and conservation biology. New York: Oxford University Press.

Fajardo, I. (200I) Monitoring non-natural mortality in the Barn Owl (Tyto alba), as an indicator of land use and social awareness in Spain. Biol. Conserv. 97: 143-149.

Fox, G. A. (2001) Failure-time analysis studying times to events and rates at which events occur. Pp. 235-266 in S. M. Scheiner and J. Gurevitch, eds. Design and analysis of ecological experiment. New York: Oxford University Press.

Gil-Sánchez, J. M., Moleón, M., Otero, M. and Bautista, J. (2004) A nine-year study of successful breeding in a Bonelli's eagle population in southeast Spain: a basis for conservation. Biol. Conserv. 118: 685-694.

Golawski, A. (2003) The occurrence of the Barn Owl Tyto alba in sacred buildings in central-eastern Poland. Ornis Hung. 1213: 275-277.

Gowaty, P. A. and Bridges, W. C. (1991) Nestbox availability affects extra-pair fertilization and conspecific nest parasitism in eastern bluebirds, Sialia sialis. Anim. Behav. 41: 661-675.

Hagemeijer, W. J. M. and Blair, M. J. (1997) The EBCC atlas of European breeding birds, their distribution and abundance. London: T. and A. D. Poyser.

Handrich, Y., Nicolas, L. and Le Maho, Y. (1993) Winter starvation in captive common barn-owls: physiological states and reversible limits. Auk 110: 458-469.

Kalbfleisch, J. D. and Prentice, R. L. (1980) The statistical analysis of failure time data. New York: Wiley.

Klein, Á., Nagy, T., Csörgő, T. and Mátics, R. (2003) Using ring-recapture data in Barn Owl (Tyto alba Scop., 1769) conservation. Sixth World Conference on Birds of Prey and Owls. Budapest: World Working Group on Birds of Prey and Owls, Abstract Volume 3.

König, C., Weick, F. and Becking, J.-H. (1999) Owls: A guide to the owls of the world. Mountfield: Pica Press.

Li, P. and Martin, T. E. (1991) Nest-site selection and nesting success of cavitynesting birds in high elevation forest drainages. Auk 108: 405-418.

Liebezeit, J. R. and George, T. L. (2002) Nest predators, nest-site selection, and nesting success of the dusky flycatcher in a managed ponderosa pine forest. Condor 104: 507-517.

Lovász, Gy. and Nagyváradi, L. (1997) Anthropogenic changes of the natural environment during the last 1100 years. Pp. 1-8 in G. Füleky, ed. Changes in the landscape of the Carpathian Basin since 895. Gödöllő: Gödöllői Agrártudományi Egyetem MSZKI (in Hungarian).

Mänd, R., Tilgar, V., Lõhmus, A. and Leivits, A. (2005) Providing nest boxes for holenesting birds: Does habitat matter? Biodiv. Conserv. 14: 1823-1840.

Marsden, S. J. and Jones, M. J. (1997) The nesting requirements of the parrots and hornbill of Sumba, Indonesia. Biol. Conserv. 82: 279-287.

Marti, C. D. (1999) Natal and breeding dispersal in barn owls. J. Raptor Res. 33: 181-189.

Massemin, S., Groscolas, R. and Handrich, Y. (1997) Body composition of the European 
barn owl during the nonbreeding period. Condor 99: 789-797.

Mátics, R. (2000) Mortality of the Barn Owl in Hungary based on the ringing data. Aquila 105-106: 125-133 (in Hungarian with English summary).

Mátics, R. (2005) Natural and non-natural mortality of the Barn Owl: growing importance of road death. Természetvédelmi Közlemények 11: 517-524 (in Hungarian with English summary).

Mebs, T. and Scherzinger, W. (200o) Die Eulen Europas. Stuttgart: Franckh-Kosmos.

Mikkola, H. (1983) Owls of Europe. London: T. \& A. D. Poyser.

Møller, A. P. (1989) Parasites, predators and nest boxes: facts and artefacts in nest box studies of birds? Oikos 56: 421-423.

Newton, I. (1994) The role of nest sites in limiting the numbers of hole-nesting birds: a review. Biol. Conserv. 70: 265-276.

Paredes, R. and Zavalaga, C. B. (2001) Nesting sites and nest types as important factors for the conservation of Humboldt penguins (Spheniscus humboldti). Biol. Conserv. 100: 199-205.

Pell, A. S. and Tidemann, C. R. (1997) The impact of two exotic hollow-nesting birds on two native parrots in savannah and woodland in Eastern Australia. Biol. Conserv. 79: 145-153.

Renner, M. and Davis, L. (2001) Survival analysis of Little Penguin Eudyptula minor chicks on Motura Island, New Zealand. Ibis 143: 369-379.

Roulin, A. (1999) Natural and experimental nest-switching in Barn Owl Tyto alba fledglings. Ardea 87: 237-246.

Schlaepfer, M. A., Runge, M. C. and Sherman, P. W. (2002) Ecological and evolutionary traps. Trends Ecol. Evol. 17: 474-480.

Shawyer, C. R. (1987) The barn owl in the British Isles. London: The Hawk Trust.

Taylor, I. (1994) Barn owls: predatorprey relationships and conservation. Cambridge: Cambridge University Press.

Toms, M. (1998) Project Barn Owl - nearing completion. BTO News January-February, 214.

Vilka, I. (2003) On the importance of nest box age in monitoring populations of small hole-nesting birds. Ornis Hung. 12-13: 229-236.

Zar, J. H. (1974) Biostatistical analysis. London: Prentice-Hall.

\section{ÁKOS KLEIN*}

Behaviour Ecology Group, Department of Systematic Zoology and Ecology, Eötvös Loránd University, Pázmány P. sétány 1/c., 1117 Budapest, Hungary.

\section{TIBOR NAGY}

Hungarian Barn Owl Protection Foundation, Eötvös utca 34, 2230 Gyömró, Hungary.

\section{TIBOR CSÖRGŐ}

Department of General Zoology, Eötvös Loránd University, Pázmány P. sétány 1/c., 1117 Budapest, Hungary.

\section{RÓBERT MÁTICS}

Institute of Medical Biology, Faculty of Medicine, University of Pécs, Szigeti út 22, 7601 Pécs, Hungary.

*Author for correspondence. Current address: Behaviour Ecology Group, Department of Systematic Zoology and Ecology, Eötvös Loránd University, Pázmány P. sétány 1/c., 1117 Budapest, Hungary.e-mail: akso@freemail.hu 